\title{
The Government of India's Role in Promoting Innovation through Policy Initiatives for Entrepreneurship Development
}

\author{
Ravindra Abhyankar
}

\author{
"Innovation is the specific instrument of entrepreneurship." \\ The act that endows resources with a new capacity to \\ create wealth.
}

Peter F. Drucker (1909-2005)

Author and management consultant

\begin{abstract}
In spite of having a large publicly funded science and technology infrastructure and a sizeable education base, India has not been able to realize its innovative potential due to a fragmented innovation ecosystem. The government of India has taken many initiatives towards strengthening the innovation ecosystem, the most important of which are: i) the establishment of the National Innovation Council, whose mandate is to coordinate various innovation-related activities, and ii) the new Science, Technology and Innovation Policy 2013, which is intended to promote entrepreneurship and science-led solutions for sustainable and inclusive growth. With a focus on this new policy initiative, this article describes the current innovation ecosystem and the challenges it faces, and it discusses the efforts made by the government towards the promotion of innovation for entrepreneurship development and sustainable growth. With the implementation of this new policy the early indications are that India is poised to take a big leap towards innovation-led growth.
\end{abstract}

\section{Introduction}

India is a country with over 1.2 billion people, 379 million (31\%) of which are between the ages of 18 and 35 (Census of India, 2011). And, many of these young people are in search of jobs, despite being educated. For example, only one in every four urban males under 29 years is employed even though they hold at least a certificate or diploma (National Sample Survey Office, 2013). The aim of the government has been to create employment opportunities for youth while focusing on rapid economic growth. Entrepreneurship development is one of the mechanisms adopted by the Government of India towards the creation of job opportunities. The government's assumption is that support for innovation will enhance entrepreneurship development, which will in turn accelerate economic growth.
In March 2010, Mrs. Pratibha Patil, 12th President of India, announced the government's vision by declaring the current decade as the "Decade of Innovation" (Nation Innovation Council, 2010). Several challenges to the desired creation of an ecosystem for innovation and entrepreneurship development are a cause for concern. However, there have been notable efforts taken by the government by announcing conducive policies and also efforts by various government departments towards fulfilling the above vision.

This article provides the necessary background to place the current innovation ecosystem within the Indian context, highlights some of the related challenges facing India today, and describes efforts made by the government towards the promotion of innovation for entrepreneurship development. 


\section{The Government of India's Role in Promoting Innovation}

\section{Ravindra Abhyankar}

\section{The Indian Context}

The roots of India's current economic systems extend back to the time of colonial rule and its autocratic and fragmented structure. The country was made to forcefully serve as a market to its colonial bosses and their industrial products. Independence in 1947 brought many changes, but the country did not have to start "from scratch". The foundations of the today's legal, financial, educational, bureaucratic governance systems were inherited from the colonial period. Even the roots of publicly funded research structures, which have grown large today, date back to the colonial days. However, one key area of change following independence involved the adoption of a closed economy that relied heavily on central planning, restricted imports, and nationalization of industries. Not until 1991 did India open its economy, which led to real competitiveness and a need for innovation in all industries.

India today is a vast democratic country with a population of over 1.2 billion people with diverse ethnicities, religions, and languages. Nearly $70 \%$ of Indians live in rural areas (Census of India, 2011), and over past 20 to 30 years there has been a continuous flow of people from villages towards cities, mainly in search of work (Vinayakam \& Sekar, 2013). The Indian economy is mostly based on agriculture, which depends on the unpredictable South-West monsoon. Given the large population, it is a considerable task for the government ensures adequate and affordable supplies of food, drinking water, clothing, housing, education, and healthcare.

The people of India, especially the young, crave employment. There is a limitation to employment opportunities offered by the various sectors of economy, but the government does provide employment guarantee programs. However, these programs are targeted at providing basic needs and tend to provide labour-intensive jobs that have no link with innovation. There is a realization that, "to sustain rapid growth and alleviate poverty, India needs to aggressively harness its innovative potential, relying on innovation-led, rapid, and inclusive growth to achieve economic and social transformation" (Dutz, 2007). The innovative potential of the young Indian population, if supported through an effective innovation ecosystem, holds potential for developing entrepreneurship and providing the growth and job opportunities that India needs.

\section{India's national innovation system}

The current national innovation system in India is a vast and complex system comprised of knowledge producers such as science and technology institutions, academia, and innovating individuals and knowledge users (e.g., industry-production/services in the public and private sectors). Various governments in India have given priority to science, technology, and innovation, and therefore India has evolved a large publicly funded $R \& D$ structure. There are various councils and research structures under various ministries, which cater to different research areas and which are distributed around the country. Examples include:

\section{- Council of Scientific and Industrial Research (CSIR;} csir.res.in): established in 1941; 39 laboratories

- Indian Council of Agricultural Research (ICAR; www.icar.org.in): established in 1929; 99 institutes and 17 research centres

- Indian Council of Medical Research (ICMR; icmr.nic.in): established in 1911; 30 laboratories

- Defence Research \& Development Organisation (DRDO; drdo.gov.in): established in 1958; 48 laboratories

There are many other publicly funded institutions that perform research and technology development for industries related to steel, oil and natural gas, renewable energy, coal, textiles, railways, road transport, electronics and communication, environment and forests, irrigation, and so on. There are also more than 1200 privately or state-funded Scientific and Industrial Research Organizations (SIROs; dsir.gov.in).

In academia, there are 280 universities in the public sector, including institutions of high education such as Indian Institutes of Technology (IITs) and the Indian Institute of Science (IISc), in addition to more than 150 self-financing and deemed universities. There are also more than 2500 in-house $R \& D$ centres created by corporations, and there are non-government organizations (NGOs) that use and apply the available knowledge for the benefit of the society.

Furthermore, there are financial institutions such as the Industrial Development Bank of India (IDBI) and the Small Industries Development Bank of India (SIDBI), which lend support for innovation and also for commer- 


\section{The Government of India's Role in Promoting Innovation}

\section{Ravindra Abhyankar}

cialization of innovative technologies besides entrepreneurship. Also, various fiscal incentives are offered by the Department of Scientific and Industrial Research (dsir.gov.in) towards the R\&D activities performed by institutions, academia, and industry for supporting, nurturing and leading their innovations towards fruition.

All of these institutions were working mostly in a standalone mode prior to linearization of the economy in the 1990s. Since then, strong efforts have been made to harness the innovative capabilities of these structures by connecting them to one another and to industry and society, forming an innovation ecosystem.

\section{India's innovation ecosystem}

Broadly speaking, an innovation ecosystem is a combination of two distinct but largely separated economies: i) the knowledge economy (comprised of knowledge producers), which is driven by fundamental research, and ii) the commercial economy (comprised of knowledge users), which is driven by the marketplace (Jackson, 2013). In India, the innovation ecosystem includes the entire national innovation system described in the previous section, plus individual innovators and entrepreneurs; mentors; government policies; angel, venture capital, institutional, and industrial funding mechanisms, intellectual property rights mechanisms; technology transfer mechanisms; market inputs; and incentives, awards, and other innovation-recognition mechanisms, among others. Ideally, these various structures and mechanisms facilitate the smooth translation of innovations through the various segments of a complex innovation chain that takes ideas from "mind to market".

Thus, the functional goal of the innovation ecosystem is to enable technology development and innovation. But, how well is India's innovation ecosystem performing today? According to the Global Innovation Index (WIPO, 2014), India ranks 76th among the 143 countries surveyed, having fallen 10 positions since the last report and having fallen relative to other BRIC economies (tinyurl.com/lglu9ho). A smaller slide of one position down the rankings of the Global Competitive Index leaves India in 60th position among 148 countries (Schwab, 2013). As per OECD (2007) sources:

"India's GERD [gross domestic expenditure on R\&D] was $0.76 \%$ in 2007 , essentially unchanged since $2000 \ldots$ India's innovation system is dominated by universities and PRIs [public research institutions]... Government R\&D expenditures accounted for $0.47 \%$ of GDP [gross domestic product]; Some $73 \%$ of public research is fun- ded by block grants which are allocated on the basis of national research priorities... 95\% of business research and development activities are funded by firms themselves, public financial support is negligible."

Together, these indicators suggest that, in spite of a large national innovation system, the current performance of the Indian innovation ecosystem appears weak. One may speculate that the reasons for this poor performance may be related to fragmentation and a lack of focus: the legacies and mindsets of the pre-economic liberalization era are still being carried forward by some of its constituent stakeholders. At least, this speculation finds support in the government's attempts to address many of these challenges in its recent policy on innovation (Ministry of Science and Technology, 2013). The policy initiatives undertaken by the Government of India to improve the innovation ecosystem are described below; but first, the following section presents the author's view of the current challenges facing India's innovation ecosystem.

\section{Current Challenges}

The author's view of the key challenges faced by India's innovation ecosystem and entrepreneurship in general are listed and described below:

\section{Fragmented policy and policy implementation: There} has been no comprehensive policy focusing on innovation and entrepreneurship so far. Also, the mechanisms to operate existing, fragmented policies were not uniform, which resulted in gaps in understanding and failure to achieve the desired effects of such policies.

2. Inadequate funding of $R \& D$ : Little national funding is available for R\&D: from 2011 to 2012 it was only $0.88 \%$ of gross domestic product (NSTMIS, 2013). Consequentially, even less funding is available to the academic and $R \& D$ institutions. Out of the total $R \& D$ expenditure incurred in the country, about $63 \%$ of the expenditure is incurred by the government itself and the total $R \& D$ expenditure incurred by industry altogether is equivalent to the amount just one global multinational spends on its in-house R\&D (NSTMIS, 2013).

3. Difficult and lengthy funding procedures: Although funding is available from banks and public sources the procedures for accessing such funding are often complex, cumbersome, lengthy, and bureaucratic, in other words, not conducive to innovation and entre- 


\section{The Government of India's Role in Promoting Innovation}

\section{Ravindra Abhyankar}

preneurship. Moreover, despite these difficult and lengthy procedures, the system seeks immediate returns. However, the returns from innovation are often uncertain, late, or not quantifiable immediately.

4. Angel, venture capital, and seed funding: Despite 100 angel networks operating in India (e.g., Indian Angel Network: indianangelnetwork.com; Mumbai Angels: mumbaiangels.com), only tens of deals are made each year, according to the "Report of the Committee on Angel Investment \& Early Stage Venture Capital" (Planning Commission, 2012). For such a populous country, this magnitude of deals is very low compared to the numbers from abroad and fall short of India's requirements. The report also indicates low levels of early-stage venture capital investment: around US\$ 240 million per year. And, here also, there are only few hundred deals per year. Indian angels are constrained by regulations that make investment and exit cumbersome (Planning Commission, 2012).

5. Weak linkages between stakeholders: The linkages between industry, especially medium and smallscale enterprises and $R \& D$ or academic institutions are weak. Industry requires proven technologies, but the institutions can only offer technologies at considerably earlier stages (i.e., at mostly a laboratory or pilot scale), meaning there is still much work to be done to bring the technologies to market. There is also considerably less funding and mentorship support available from the private sector. There is no easy exchange of manpower between the industries and academia or R\&D institutions, which limits their capacity for mutual understanding and technology transfer.

6. Non-conducive education system: The general education system is still too focused on grades and careers and is not oriented toward innovation and entrepreneurship. This situation is further worsened by the inherent problems of lack of infrastructure and good facilities in the educational institutions; delays in the funding system; and delays in the funds or other support reaching innovation projects. While industry craves solutions to their problems, the academic institutions are generally too busy performing routine academic exercises, churning out educated manpower that is often ill suited to either innovative industries or entrepreneurship. However, exceptions to this general view include a few high-end academic institutions such as Indian Institutes of Technology and similar institutions.
7. Poor infrastructure facilities in villages: Basic infrastructure facilities such as electricity, Internet, roads and rail, and even the availability of a skilled workforce, are not evenly distributed in India and often weak in smaller cities or towns and rural parts of the country. Thereby, there is less scope for innovation and entrepreneurship to flourish in such areas. In most cases, innovators and entrepreneurs must travel long distances - at their own expense - to receive mentorship or other support.

8. Risk aversion among entrepreneurs: Indian entrepreneurs often seek established technology as a basis for starting their business; they are hesitant to take on innovative ideas because of the risks involved, including the low availability and high cost of funds that often arrive too late. As a result, they look for minimum risk and quick returns. The potentially higher returns from innovation take time to realize, and not enough entrepreneurs are willing (or able) to accept the risks.

9. Inadequate protection of intellectual property rights: In India, the intellectual property regime is weak. Innovators do not generally seek protection for their intellectual property unless forced to. For most entrepreneurs, patents and other forms of protection take too long and cost too much. Patent literacy is very low, even among educated innovators, and there is a lack of expert help available, except in the medicine and pharmaceutical industry.

\section{New Policy Initiatives}

As mentioned earlier, the Government of India declared 2010-2020 as the "Decade of Innovation", for which the roadmap would be prepared by the newly established National Innovation Council (NInC; innovationcouncil.gov.in). The National Innovation Council is "the first step in creating a crosscutting system which will provide mutually reinforcing policies, recommendations and methodologies to implement and boost innovation performance in the country" (Nation Innovation Council, 2010). The Science, Technology and Innovation Policy 2013 outlines the major policy initiatives to strengthen the innovation ecosystem and give a boost to the development of innovation-led entrepreneurship in India:

"The guiding vision of aspiring Indian STI [Science, Technology, and Innovation] enterprise is to accelerate the pace of discovery and delivery of science-led solutions for faster, sustainable and inclusive growth. A 


\section{The Government of India's Role in Promoting Innovation}

\section{Ravindra Abhyankar}

strong and viable Science, Research and Innovation System for High Technology-led path for India (SRISHTI) is the goal of the new STI policy." (Ministry of Science and Technology, 2013).

Below, the key initiatives of this policy are explored in light of the challenges identified in the previous section:

1. Funding: The policy announces an increase in the gross expenditure in research and development (GERD) from less than $1 \%$ to $2 \%$ of the gross domestic product over the next five years. It also states that a National Science, Technology and Innovation Foundation will be established "as a public-private partnership (PPP) initiative for investing critical levels of resources in innovative and ambitious projects" (Ministry of Science and Technology, 2013), thus attracting private sector investments in R\&D. It further announces the establishment of a fund for innovations for social inclusion, "small idea-small money", and a "risky idea fund". These funds are designed to address the funding-related challenges described in the previous section. The policy does not mention angel or venture capital funding but the above measures will fulfill some of the requirements of innovators and entrepreneurs and the innovation ecosystem overall. It also addresses the "rigidities" in centrally developed plans for investment and assures a flexible approach that allows fine tuning of the government's five-year plans in response to rapidly changing science and technology, and it addresses the challenge of outdated procedures adopted for funds disbursement for innovative projects.

2. Strengthening the linkages between stakeholders: The policy calls for "special and innovative mechanisms for fostering academia-research-industry partnerships" and facilitating the "mobility of experts from academia to industry and vice versa" (Ministry of Science and Technology, 2013). This initiative should help address the challenge related to linkages and should facilitate understanding within such partnerships.

3. Promotion of science: The policy promotes the spread of scientific interest and understanding across all sections of society. The policy will "further enable school science education reforms by improving teaching methods, science curricula, motivating science teachers and schemes for early attraction of talent to science" (Ministry of Science and Technology, 2013). In these ways, the policy addresses the need for educational reforms.
4. Risk taking ability: The policy accepts risk as an integral part of a vibrant innovation system. The policy emphasizes risk sharing by the government, which is slated to "significantly increase private sector investment in R\&D and technology development" and "new financing mechanisms would be created for investing in enterprises without fear of failure" (Ministry of Science and Technology, 2013).

5. Intellectual property: The policy will seek to "establish a new regulatory framework for data access and sharing [and for the] creation and sharing of intellectual property. The new policy framework will enable strategic partnerships and alliances with other nations through both bilateral and multilateral cooperation in science, technology and innovation. Science diplomacy, technology synergy and technology acquisition models will be judiciously deployed based upon strategic relationships" (Ministry of Science and Technology, 2013). Thus, this initiative is very important for international collaborations.

6. Addressing the innovation value chain: The policy also enables a holistic approach to the complex value chain of innovation by providing science and technology interventions at all levels of research, technology and manufacturing, and services in the areas of socioeconomic importance. In this way, the policy has a very positive note and expresses a desire to shape the future of India. With the advantages of a "large demographic dividend" and a "huge young talent pool", the policy foresees the achievement of national goals for sustainable and inclusive growth (Ministry of Science and Technology, 2013).

7. Participation in global $R \& D$ infrastructure: The policy proposes the creation of "high-cost global infrastructure in some fields through international consortia models. Indian participation in such international projects will be encouraged and facilitated to gain access to facilities for advanced research in cutting edge areas of science. This will also enable the Indian industry to gain global experience and competitiveness in some high-technology areas with spin-off benefits" (Ministry of Science and Technology, 2013).

The Science, Technology and Innovation Policy 2013 thus tries to join the fragmented pieces of the Indian innovation ecosystem and bring it into the sharper focus. It addresses the need to enhance scientific understanding and skills among the young and aspires to position India among the top five global scientific powers by 2020. It also links the contributions of science, research, 


\section{The Government of India's Role in Promoting Innovation}

\section{Ravindra Abhyankar}

and innovation with an inclusive growth agenda with the aim of forming a robust and focused national innovation system. Importantly the policy supports entrepreneurship driven by science, technology, and innovation with viable and highly scalable business models. A key mechanism is investment in young innovators and entrepreneurs through education, training, and mentoring. This positive signs indicate that the government has fulfilled its role on the policy front. Now, it will be up to all the departments of the government to build innovative delivery mechanisms to take the fruits of this policy to the people of the country.

\section{Other Government Initiatives}

In this section, other government initiatives beyond the scope of the Science, Technology and Innovation Policy 2013 are described.

\section{Lead paper on technology and innovation for the current five-year plan}

India follows five-year plans for planning and implementation, and the 12th Five Year Plan (2012-2017) includes a lead paper on "Technology and Innovation" (Planning Commission, 2011), which says that:

"Strengthening the innovation ecosystem requires a platform for information sharing and dissemination to ensure: (1) improved access to knowledge and (2) support in the form of resources, linkages, mentoring and outreach. Greater knowledge of innovations can stimulate their adoptions on a longer scale. This decentralized, open and networked model would enable information sharing on innovations and collaboration among stakeholders."

\section{India Inclusive Innovation Fund}

The India Inclusive Innovation Fund (tinyurl.com/ m5n6864) is designed to "combine innovation and dynamism of enterprises to solve the problems of the bottom of the pyramid in India" (National Innovation Council, 2014). The initial investment of INR 500 crores (approximately $\$ 83$ million USD) is slated to expand 10 times. The government will contribute $20 \%$ of the fund, and the rest will come from financial institutions, insurance companies, multilateral/bilateral development agencies, and Indian and global corporations. The life of the fund is nine years, and it will focus on healthcare, food and nutrition, agriculture, education energy, financial inclusion, and environment technology, among other areas.
Initiatives from the Ministry of Science and Technology The following initiatives have been undertaken by the Ministry of Science and Technology:

1. Biotechnology Industry Research Assistance Council (birac.nic.in)

2. India Innovation Growth Program (www.indiainnovates.in)

3. National Innovation Foundation (nif.org.in)

4. Promoting Innovation in Individuals, Start-ups and MSMEs (PRISM; www.dsir.gov.in/12plan/prism/prism.htm)

5. Council of Scientific and Industrial Research Innovation Complexes (www.csir.res.in)

6. Patent Assistance Programs operated by the Technology Information, Forecasting and Assessment Council (tifac.org.in) and the National Research Development Corporation (nrdcindia.com)

7. Technology Business Incubators operated by the Department of Science and Technology (dst.gov.in)

8. Small Business innovation Research Initiative (sbiri.nic.in)

9. Technology Development and Demonstration Program (tinyurl.com/mbfxedv)

Programs by other ministries

There are other schemes created by various other ministries, including the following:

1. Various programs from the Ministry of New and Renewable Energy (mnre.gov.in)

2. The Information Technology and Research Academy (medialabasia.in/itra/itra/) from the Ministry of Communication and Information Technology

\section{Conclusion}

India has a large, demographically diverse population, with many young people seeking employment. The country is on a path to growth, but the rate of growth has been slow. The government has realized the roots of the basic problems and made appropriate reforms, 


\section{The Government of India's Role in Promoting Innovation}

\section{Ravindra Abhyankar}

mainly in the areas of administration, economy, and labour, as it tries to free itself from negative aspects of its colonial legacy. There has been a substantial thrust toward science, technology, and innovation in past 20 years, and many initiatives have been undertaken in that direction. However, the investments in science, technology, and innovation are not yet translating into the desired reality. Realizing that the innovation-led entrepreneurship development holds promise for growth, the government has taken major policy initiatives with a strong innovation agenda.

There are formidable challenges in realizing the goal, but as this article has shown, the Science, Technology and Innovation Policy 2013 is a big step in the right direction, because it addresses most of the key challenges in developing an effective innovation ecosystem. The main initiatives are provision of funds and removing the sluggishness in the ecosystem for innovations by improving linkages and making it vibrant in a comprehensive way. The policy is in place; now, its success depends on its implementation. Some time will needed before conclusions can be drawn about the policy's ultimate effects on the growth path. However, the new direction reflects strong growth aspirations and resonates with the zeal and zest of the youth who wish to journey on the risky path of innovation-based entrepreneurship.

\section{References}

Census of India. 2011. Population Enumeration Data. Government of India: Office of the Registrar General \& Census Commissioner.

Dutz, M. A. 2007. Unleashing India's Innovation: Towards Sustainable and Inclusive Growth. Washington, DC: The World Bank.

Jackson, D. J. 2013. What Is an Innovation Ecosystem? Arlington, VA: National Science Foundation.

Ministry of Science and Technology. 2013. Science, Technology and Innovation Policy 2013. Delhi: Government of India.

National Innovation Council. 2010. Decade of Innovation. Government of India: National Innovation Council.

National Innovation Council. 2014. Government to Launch India Inclusive Innovation Fund - Press Note. Government of India: National Innovation Council.

National Sample Survey Office. 2013. Key Indicators of Employment and Unemployment in India 2011-12, 68th Round. Government of India: National Sample Survey Office.

\section{About the Author}

Ravindra Abhyankar is an Electrical Engineer who has worked in the Government of India in various capacities. After working for 17 years in the Ministry of Defense (1974-1990) in the field of quality assurance, technical development, and indigenization of various fighter aircraft and other aeronautical systems, he joined the Ministry of Science and Technology in the Department of Scientific and Industrial research (DSIR). In this ministry, he handled various responsibilities such as administering fiscal incentives for $R \& D$ and supporting innovation at the individual and industrial levels for over 20 years (1990-2011). He was the nodal officer in the Government of India for the Asian and Pacific Center for Transfer of Technology (APCTT), which is a United Nations initiative dedicated to capacity building of Asia-Pacific countries to nurture and promote national innovation systems and also to create enabling environments for the development and transfer of technology and $R \& D$ management. He has also functioned as an Adviser to the Science and Technology Minister of Mozambique (2012-2014) in the creation of a publicly funded $R \& D$ system for the benefit of Mozambican industry.

NSTMIS. 2013. Research and Development Statistics at a Glance 201112. Government of India: National Science and Technological Management Information System.

Planning Commission. 2011. Twelfth Five Year Plan: Technology and Innovation. Government of India: Planning Commission.

Planning Commission. 2012. Creating a Vibrate Entrepreneurial Ecosystem in India: Report of the Committee on Angel Investment \& Early Stage Venture Capital. Government of India: Planning Commission.

Schwab, K. (Ed.). 2013. The Global Competitiveness Report 2013-2014: Country Profile Highlights. Geneva: World Economic Forum.

WIPO. 2014. The Global Innovation Index 2014: The Human Factor in Innovation. Fontainebleau, Ithaca, and Geneva: Cornell University, INSEAD, and the World Intellectual Property Organization (WIPO).

Vinayakam, K., \& Sekar, S. P. 2013. Rural to Urban Migration in an Indian Metropolis: Case Study Chennai City. IOSR Journal of Humanities and Social Science, 6(3): 32-35. http://dx.doi.org/10.9790/0837-0633235 